\title{
Experimental Study on the Thermal Decomposition of Two Nitrocellulose Mixtures in Different Forms
}

\author{
Wenzhong MI ${ }^{1,2}$, Ruichao WEI ${ }^{1,3}$, Tiannian ZHOU ${ }^{1}$, Junjiang HE ${ }^{1}$, Jian WANG $^{1 *}$ \\ ${ }^{1}$ State Key Laboratory of Fire Science, University of Science and Technology of China, Hefei, Anhui 230026, PR China \\ ${ }^{2}$ Fire Department of Ministry of Public Security, Beijing 100054, China \\ ${ }^{3}$ Department of Civil and Architectural Engineering, City University of Hong Kong, Hong Kong 999077, PR China \\ crossref http://dx.doi.org/10.5755/j01.ms.25.1.18907
}

Received 26 August 2017; accepted 18 February 2018

\begin{abstract}
In order to ensure the safety of nitrocellulose (NC) mixtures in storage, transportation and usage, it is necessary to study the thermal stability of $\mathrm{NC}$ mixtures. In the present study, the thermal decomposition of two commonly used nitrocellulose mixtures with different forms including soft fiber form and white chip form were investigated. Experimental results by differential scanning calorimeter (DSC) and simulation results by thermal safety software (TSS) were compared. The detailed structures of the two mixtures were also revealed by scanning electron microscope (SEM). It was found that the thermal properties such as onset decomposition temperature, maximum decomposition temperature, and temperature range of decomposition exhibit a difference between two forms of NC. Meanwhile, the effect of varying heating rates $(5,10,15$, and $20^{\circ} \mathrm{C} / \mathrm{min}$ ) on thermal stability of $\mathrm{NC}$ with two forms was discussed. The results showed that the decomposition temperature increases with the increasing heat flow. Methods proposed by Ozawa and Kissinger presented a positive fitting result and similar calculated thermal kinetic parameters, indicating that the NC mixtures used in the present study follow a single-stage reaction. The simulation results also verified the applicability of the autocatalytic reaction for the two NC mixtures. The calculated activation energy of the simulation method is lower than that of the Ozawa and Kissinger methods. The results of all three methods show that the activation energy of NC-F is higher than NC-C.

Keywords: nitrocellulose, forms, thermal decomposition, thermal kinetic, simulation.
\end{abstract}

\section{INTRODUCTION}

Nitrocellulose (NC) is widely exploited as additive in explosives, propellants, lacquers, films and celluloid products [1]. However, this energetic material is prone to release heat by decomposition at elevated temperature, sometimes even room temperature [2]. If there is poor heat dissipation during storage, $\mathrm{NC}$ will heat up rapidly and burn spontaneously [3]. The parameters and mechanisms of thermal decomposition of $\mathrm{NC}$ are of crucial importance. In recent years, NC has caused several major accidents [4]. For instance, at 10: 51: $46 \mathrm{pm}$ on August 12, 2015, a fire occurred in a container with $\mathrm{NC}$ in the storage yard of Ruihai Company. Gases were generated, meanwhile, the temperature and pressure in the container increased gradually, which destroyed the container and caused the spread of the fire. Consequently, the fire caused two explosions of ammonium nitrate. The direct economic loss was approximately 6.866 billion yuan. Furthermore, the accident caused 165 deaths, 798 injuries, and 8 missing $[3,5]$. Thus, it is necessary to study the thermal behavior of $\mathrm{NC}$, which is conducive to evaluating the thermal stability of such materials.

Pure nitrocellulose $\left(\mathrm{C}_{12} \mathrm{H}_{16} \mathrm{~N}_{4} \mathrm{O}_{18}\right)$ is a white fibrous solid and very unstable $[6,7]$. It is usually mixed with other humectants or plasticizers to increase its stability and/or meet the needs of different applications. White soft fiber NC (NC-F) and white chip NC (NC-C) are two common NC. The NC-F, as Fig. 1 a shows, is a flocculent mixture of NC fiber and water or alcohol. In contrast, as Fig. $1 \mathrm{~b}$ shows, the $\mathrm{NC}-\mathrm{C}$ is a combination of $\mathrm{NC}$ fiber and some plasticizer that are compressed together to form chips, which are not deformed easily when point pressure is applied. Compared with NC-C, NC-F exhibits distinctive characteristics such as high density, high gloss, and less dust. More information about two different forms of $\mathrm{NC}$ is given in subsection 2.1.

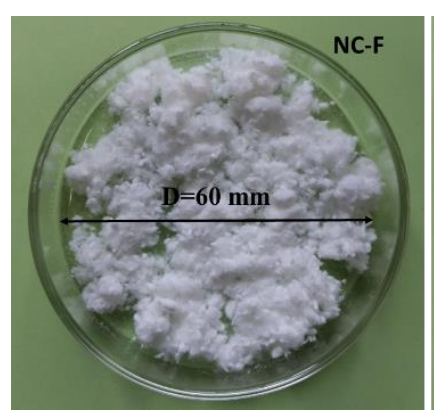

a

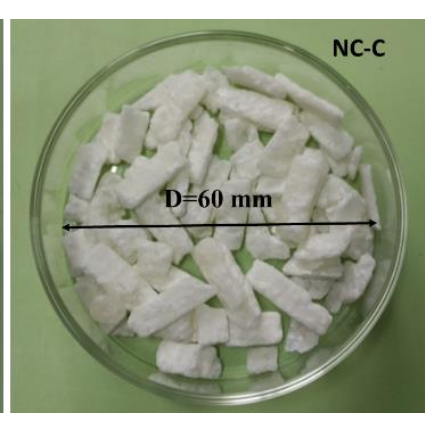

$\mathrm{b}$
Fig. 1. Comparison of the macroscopic product structures: $\mathrm{a}-\mathrm{NC}-\mathrm{F} ; \mathrm{b}-\mathrm{NC}-\mathrm{C}$

The size of reacting particles affects system such as propellants, pyrotechnics, and explosives. These reactive systems can involve powders, slurries, or dispersions of a solid [8]. It is also well-known that the physical form of solid fuels affects their ignition and burning characteristics. For example, wood with the same species in sawdust, cribs and solid timber forms will burn differently [9-11].

\footnotetext{
* Corresponding author. Tel.: +86-0551-63606463; fax: +86-055163601669. E-mail address: wangj@ustc.edu.cn (J. Wang)
} 
Moreover, previous research [12] has shown that the fire properties of NC-F and NC-C have much difference. On this basis, it can be hypothesized that the thermal behavior of $\mathrm{NC}-\mathrm{F}$ and $\mathrm{NC}-\mathrm{C}$ is also different. In previous literatures, there are few researches to investigate the effect of physical form on thermal stability of NC mixtures. The infrared spectroscopic was employed by Phillips et al. [13] to measure the changes of thin NC film with plasticizer (tri-2ethylhexyl phosphate) as a function of time. The experimental results demonstrated that a plasticized nitrocellulose film decomposes at the same rate as an unplasticized film. Sovizi et al. [14] investigated the thermal stability of micron and nano-sized NC and found that the particle size of $\mathrm{NC}$ could affect its thermal stability, i.e., the decomposition temperature decreases with decreasing of particle size.

In addition, a series of experimental and theoretical researches [15-19] were conducted by means of TGDTA/DSC to study the mechanisms of pyrolysis reaction of energetic material mixtures and calculate the parameters of the thermal behavior. Wherein, Pourmortazavi et al. [20] studied the effect of nitrate content on thermal decomposition of $\mathrm{NC}$ with varying heating rates and the results showed that as the nitrate content of $\mathrm{NC}$ was raised, the heat of decomposition obtained by the peak area was reduced. Thermal safety software (TSS) is a kind of conventional software, which has been widely employed to assess the thermal kinetic parameters of energetic materials. [21] You et al. [22] employed TSS to simulate the thermal explosion development of lauroyl peroxide (LPO). They put forward that it is necessary to combine calorimetric experiment and model simulation to analyze thermal hazard for comprehensive and accurate analyses. Lin et al. [23-26] have established a reliable analysis model based on TSS to evaluate the thermal kinetic parameters of gun propellant (GP) [23], tert-butyl peroxybenzoate (TBPB) [24], Octahydro-1, 3, 5, 7-tetranitro-1, 3, 5, 7-tetrazocine (HMX) $[25,26]$, and 2, 4, 6, 8, 10, 12-Hexanitro-2, 4, 6, 8, 10, 12hexaaza-isowurtzitane (HNIW) [26]. No relevant literature has yet been found to employ the TSS to investigate the thermal kinetics of NC.

In order to identify and understand the distinction caused by different forms of $\mathrm{NC}$, and optimize the strategies and procedures during the manufacturing, transport and storage for the different forms of $\mathrm{NC}$, a comprehensive investigation on their thermal properties is urgently needed. The aim of the current study is to meet this requirement by the experimental means. In total, two experimental apparatuses, comprising the scanning electron microscope (SEM) and the differential scanning calorimeter (DSC), were employed to reveal the differences of the two NC samples in the microscopic structures and the thermal properties. The TSS was also exploited to simulate the DSC curves of NC mixtures. The simulation results were used to compare with those based on Ozawa method [27] and Kissinger method [28].

\section{EXPERIMENTAL DESCRIPTION}

\subsection{Samples}

NC-F and NC-C samples used in this work are produced by Sichuan Nitrocell Co., Ltd (Luzhou, China). The physical parameters of the two samples obtained from the product brochure are listed in Table 1 . In addition, some thermal-chemical properties of the component materials in NC mixtures are listed in Table 2.

Table 1. Physical parameters of samples

\begin{tabular}{|l|c|c|}
\hline Material & NC-F & NC-C \\
\hline Apparent density, $\mathrm{kg} / \mathrm{m}^{3}$ & 250 & 600 \\
\hline Nitrogen content, $\%$ & 12.00 & 12.00 \\
\hline Plasticizer and content & - & $\begin{array}{c}\text { Dibutyl phthalate } \\
\text { (DBP) 19.5 wt.\% }\end{array}$ \\
\hline Humectant and content & $\begin{array}{c}\text { Isopropanol } \\
29 \text { wt.\% }\end{array}$ & - \\
\hline
\end{tabular}

Table 2. Thermal-chemical properties of the component materials

\begin{tabular}{|l|c|c|c|}
\hline Material & Isopropanol & $\begin{array}{c}\text { Dibutyl } \\
\text { phthalate }\end{array}$ & $\mathrm{NC}$ \\
\hline Chemical equation & $\mathrm{C}_{3} \mathrm{H}_{8} \mathrm{O}$ & $\mathrm{C}_{16} \mathrm{H}_{22} \mathrm{O}_{4}$ & $\mathrm{C}_{12} \mathrm{H}_{16} \mathrm{~N}_{4} \mathrm{O}_{18}$ \\
\hline Molar mass & 60.06 & 278.34 & 504.28 \\
\hline Density, g/cm ${ }^{3}$ & 0.786 & 1.053 & 1.673 \\
\hline Flash point, ${ }^{\circ} \mathrm{C}$ & 12 & 188 & 4.4 \\
\hline $\begin{array}{l}\text { Heat of } \\
\begin{array}{l}\text { combustion, } \\
\mathrm{kJ} / \text { mol }\end{array}\end{array}$ & 1984.7 & - & $2101.3[29]$ \\
\hline
\end{tabular}

\subsection{Apparatus and methods}

\subsubsection{SEM}

The Philips XL30 ESEM-TMP SEM camera was used to distinguish the difference in physical microcosmic forms of the two NC samples. The accelerating voltage of the SEM was $20 \mathrm{kV}$, and the magnifications used in the present experiments were 1000,500,300, and 100, respectively.

\subsubsection{DSC}

Thermochemical behavior of NC samples with different forms was determined. The DSC curves were measured by a differential scanning calorimeter whose model number is Netzsch STA 449 F3. The experimental temperature range is $30-500{ }^{\circ} \mathrm{C}$ with the heating rate of $5,10,15$, and $20{ }^{\circ} \mathrm{C} / \mathrm{min}$, respectively. The environment gas and purge gas is nitrogen under the flow rate of $50 \mathrm{ml} / \mathrm{min}$. The aluminum oxide crucible is used in the experiments, and the cylindrical crucible has a diameter of $6.8 \mathrm{~mm}$, a height of $4 \mathrm{~mm}$, and a wall thickness of $0.5 \mathrm{~mm}$. The sample mass in each experiment was $2 \mathrm{mg}$ and the error caused by weighing should not exceed $0.2 \mathrm{mg}$.

\subsubsection{Reliable thermal kinetic parameters simulation}

Most simulation of kinetic models involve complex multi-stage reactions, which consist of several independent, parallel, and consecutive stages [23-26]. Simple singlestage reaction is given as:

$\frac{d \alpha}{d t}=k_{0} e^{\frac{-E_{a}}{R T}} f(\alpha)$.

Single-stage model for generalized autocatalysis can be expressed as:

$\frac{d \alpha}{d t}=k_{0} e^{\frac{-E}{R T}}(1-\alpha)^{n_{1}}\left(\alpha^{n_{2}}+z\right)$,

where $\alpha$ is the degree of conversion of a reaction or stage, $t$ is the reaction time, $k_{0}$ is the pre-exponential factor, $E$ is the 
activation energy, $R$ is the gas constant, $T$ is the absolute temperature, $f(\alpha)$ is the kinetic functions of a reaction or stage, $z$ is the autocatalytic constant, and $n_{1}$ and $n_{2}$ are the reaction orders of specific stages.

In the present study, single-stage simulation of generalized autocatalysis Eq. 2 will be examined.

\section{RESULTS AND DISCUSSION}

\subsection{Results of SEM analysis}

The microcosmic structures with four different magnifications, examined by Scanning Electron Microscope (SEM), are shown in Fig. 2. At a higher magnification $(25 \mu \mathrm{m}$ and $50 \mu \mathrm{m}$ scales), NC-F appears smooth surface except some minor flaws, but NC-C presents a molten and adhesion state. At a lower magnification $(50 \mu \mathrm{m}$ and $100 \mu \mathrm{m}$ scales), twining fibrous micro structures without any agglomeration are clearly observed for NC-F, while the agglomerate fibers are displayed for NC-C. The similar SEM images of micron-sized NC fibers were examined by previous research [14], and both NC-F and NC-C have $20-30 \mu \mathrm{m}$ average size in diameter.
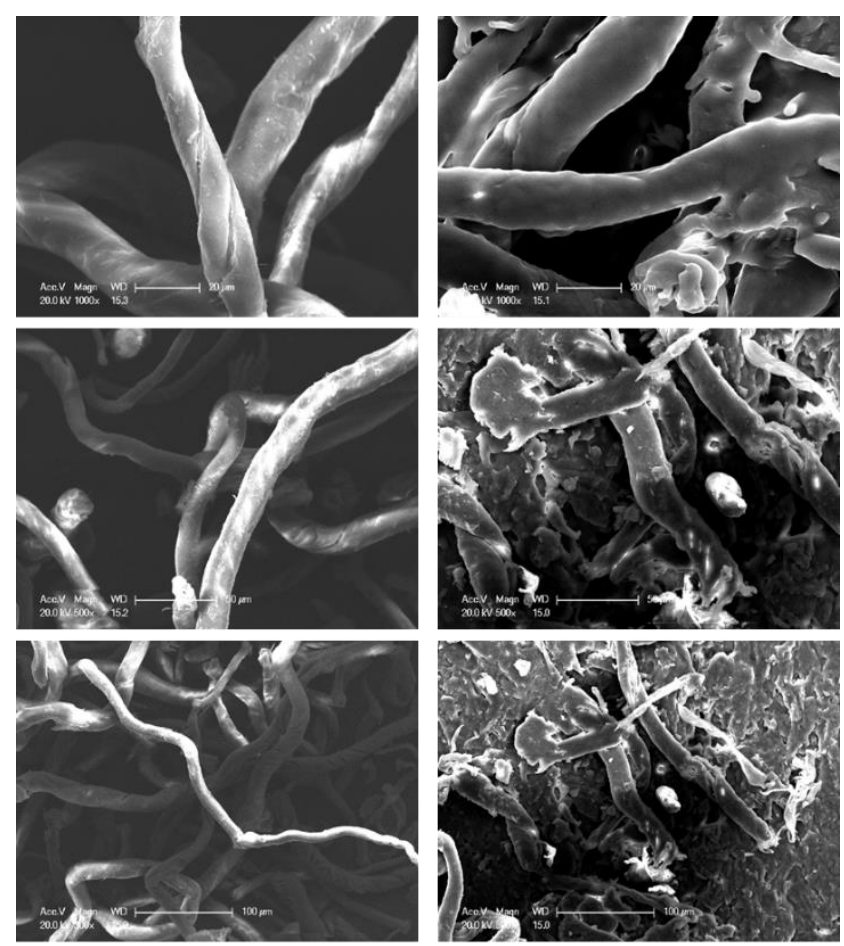

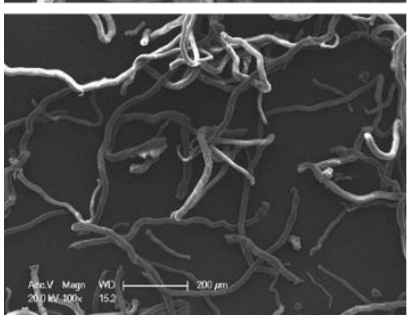

a

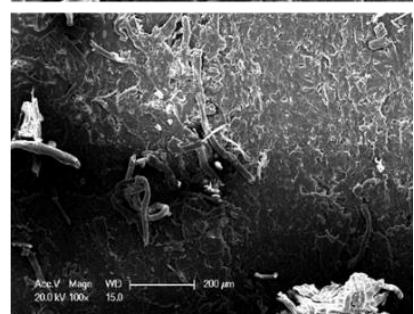

b
Fig. 2. Comparison of the microcosmic structures: a-NC-F; $\mathrm{b}-\mathrm{NC}-\mathrm{C}$

\subsection{Results of thermal analysis}

The typical DSC-TGA curves of the two samples with the heating rate of $5{ }^{\circ} \mathrm{C} / \mathrm{min}$ are presented in Fig. 3, in which a sharp drop of weight accompanied with a significant exothermic peak can be observed.

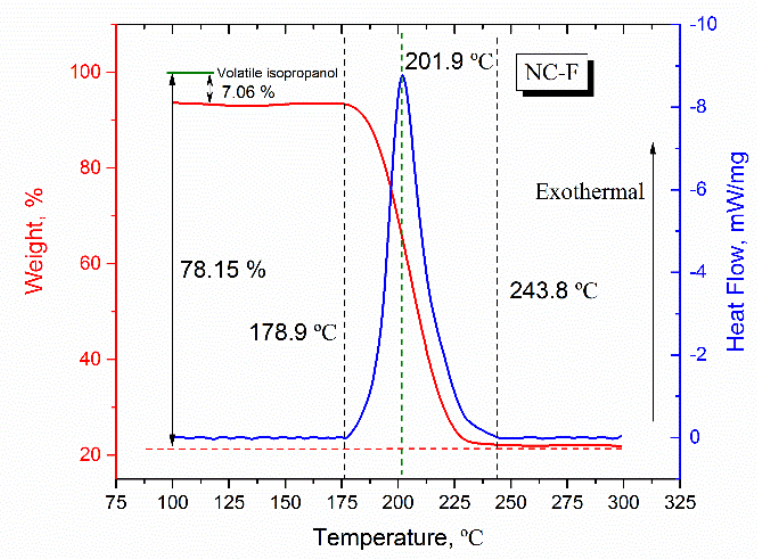

a

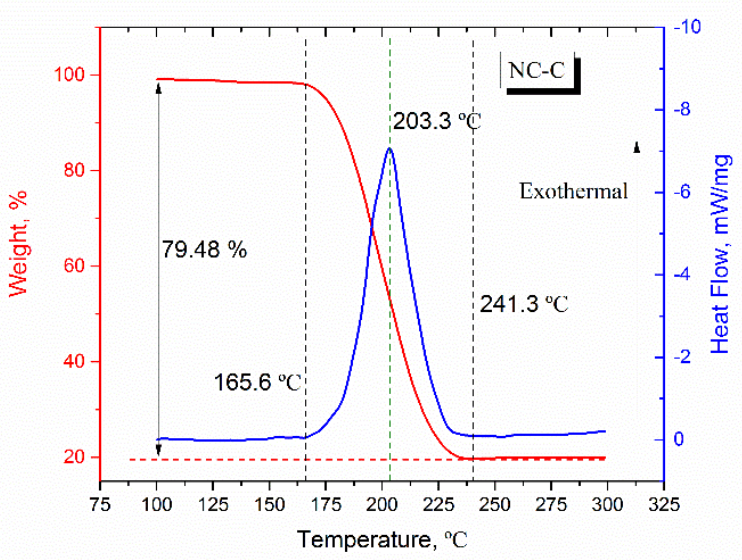

b

Fig. 3. DSC-TGA curves of $\mathrm{NC}$ mixtures with heating rate of $5{ }^{\circ} \mathrm{C} / \mathrm{min}$ : $\mathrm{a}-\mathrm{NC}-\mathrm{F} ; \mathrm{b}-\mathrm{NC}-\mathrm{C}$

For NC-F, the evaporation content of isopropanol is about 7.06 wt.\% before the decomposition, and the onset decomposition temperature is approximately $178.9^{\circ} \mathrm{C}$, followed by the maximum exothermic reaction temperature of $201.9^{\circ} \mathrm{C}$. After the decomposition, the NC-F decomposes approximately $78.15 \%$ of the total mass, which is close to NC-C with $79.84 \%$ of the total mass loss. Sovizi et al. [14] investigated the effect of particle diameter on the thermal decomposition of NC and found that the onset decomposition temperature and maximum decomposition temperature with the heating rate of $5{ }^{\circ} \mathrm{C} / \mathrm{min}$ for pure micron-sized $\mathrm{NC}$ are $192.2^{\circ} \mathrm{C}$ and $201.8^{\circ} \mathrm{C}$, respectively, whose temperature range is smaller than that of NC-F. This difference may be attributed to the humectant isopropanol in NC-F. Besides, it should be noted that the decomposition temperature range of NC-C is larger than NC-F due to the effect of the plasticizer DBP. However, the results in the current study have a distinct difference from that of NC films used by Phillips et al. [13]. The discrepancy may be attributed to the different plasticizers and forms of NC. The critical experimental results corresponding to Fig. 3 are listed in Table 3, where $T_{0}$ is the onset decomposition temperature, $T_{m}$ is the 
maximum decomposition temperature, and $T_{r}$ is the temperature range of decomposition of NC mixtures.

Table 3. The critical experimental results for DSC curves of NC mixtures

\begin{tabular}{|c|c|c|c|c|}
\hline No. & Sample & $T_{0},{ }^{\circ} \mathrm{C}$ & $T_{m},{ }^{\circ} \mathrm{C}$ & $T_{r},{ }^{\circ} \mathrm{C}$ \\
\hline 1 & NC-F & 178.9 & 201.9 & $178.9-243.8$ \\
\hline 2 & NC-C & 165.6 & 203.3 & $165.6-241.3$ \\
\hline
\end{tabular}

\subsection{Effect of heating rate}

The DSC curves of two NC samples with different heating rates are presented in Fig. 4.

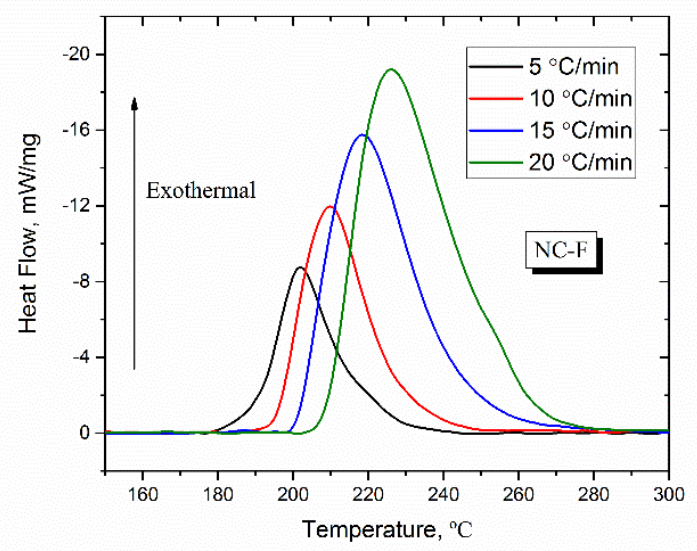

a

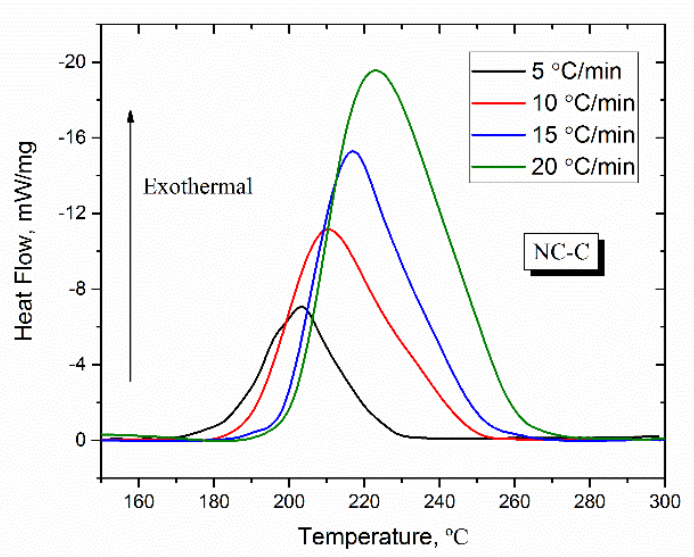

b

Fig. 4. The effect of different heating rate on the DSC results of NC: $a-N C-F ; b-N C-C$

It was observed that the temperature range of decomposition $T_{r}$ of NC-C is larger than NC-F in the range of $5-20{ }^{\circ} \mathrm{C} / \mathrm{min}$ ), which may be attributed to the influence of the plasticizer (DBP) in NC-C. In addition, the important parameters, including the onset and the maximum decomposition temperature, increase with the increasing of heating rate, as shown in Fig. 5.

\subsection{Kinetic methods}

Assuming the samples follow a single-stage reaction. Then, the Ozawa method [27] presented in Eq. 3 can be employed to calculate the activation energies of NC-F and NC-C. $\lg \beta=-1.052\left(\frac{E}{R T_{m}}\right)-2.315+\lg \frac{A_{T} E}{R}-\lg g(\alpha)$,

where $\beta\left(\mathrm{K} \mathrm{min}^{-1}\right)$ is heating rate, $A_{T}$ is the frequency factor for thermal decomposition, and $g(\alpha)$ is a function of $\alpha$.

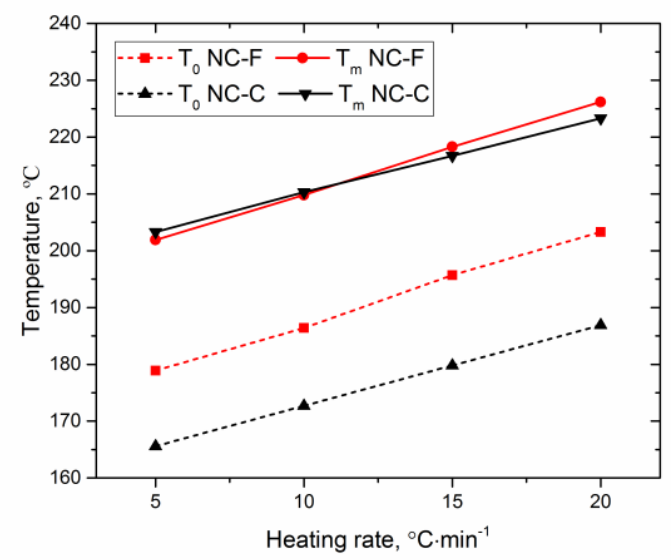

Fig. 5. Variation of the onset and the maximum decomposition temperatures of the two NC mixtures

In order to verify the availability of the Ozawa method [27], another alternative method of Kissinger method [28] is also used in the present study, expressed as:

$\operatorname{In}\left(\frac{\beta}{T_{m}^{2}}\right)=-\frac{E}{R} \frac{1}{T_{m}}+\operatorname{In}\left(\frac{R A_{T}}{E}\right)$.

Fig. 6 shows the best fit line based on the two methods.

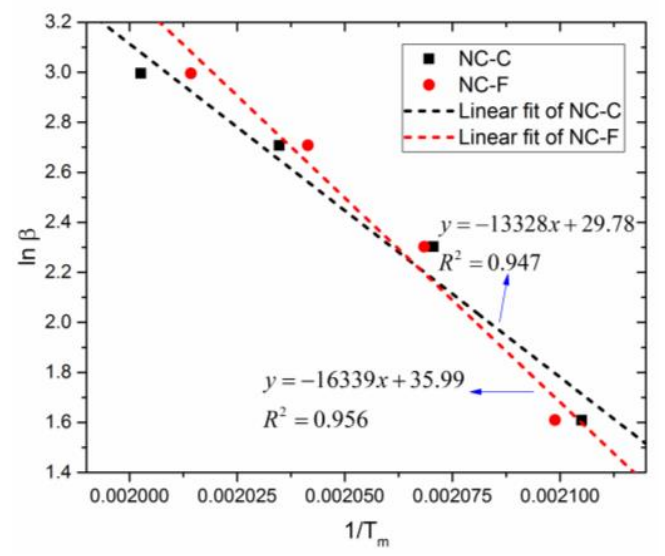

a

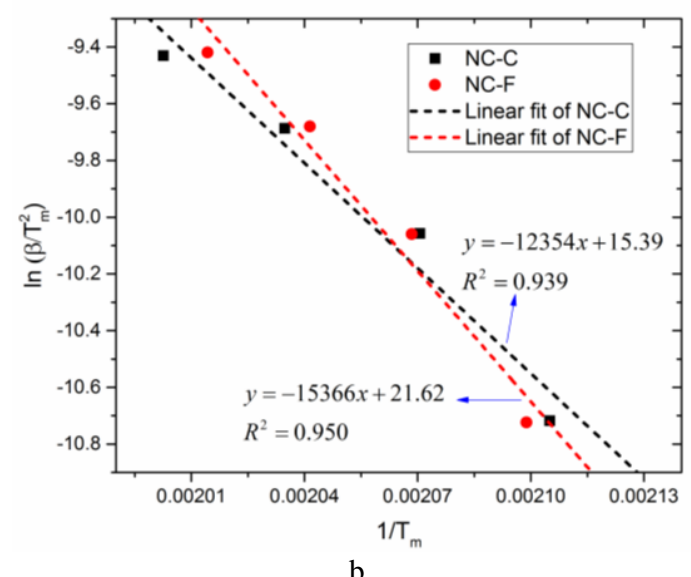

Fig. 6. Best fit line based on a-Ozawa method; $b$-Kissinger method 
The regression correlation coefficient $R^{2}$ are all greater than 0.939 . The activation energies can be estimated from the slopes of the regression lines. The positive fitting results illustrate the applicability of the single-stage assumption for the two samples.

Single-stage autocatalytic simulation was employed to examine the DSC results of NC-F and NC-C. The simulation results of non-isothermal experiments are presented in Fig. 7. It is clearly observed that the DSC curves of two NC samples are consistent well with the autocatalytic simulation in the present study. However, it is noteworthy that the calculated activation energies shown in Table 4 is much lower than Ozawa and Kissinger methods. This is probably due to the fact that the simulated method takes into account not only the maximum decomposition temperature, but also the initial decomposition temperature.

After obtaining the kinetic parameters, the enthalpy of activation, related to the activation energy, can be calculated from the following equation $[30,31]$ :

$\Delta H^{*}=E-R T_{m 0}$.

The calculated kinetic parameters ( $E$ and $\left.\Delta H^{*}\right)$ are listed in Table 4, which shows that, for an identical sample, the parameters obtained from the two methods are in good agreement except that the values based on Ozawa method are a little higher than Kissinger method. In addition, the values of $E$ and $\Delta H^{*}$ of NC-C are greater than NC-F.

Table 4. The kinetic parameters of NC-F and NC-C obtained from Ozawa method and Kissinger method.

\begin{tabular}{|c|c|c|c|}
\hline Sample & Method & $E, \mathrm{~kJ} \cdot \mathrm{mol}^{-1}$ & $\begin{array}{c}\Delta H^{*}, \\
\mathrm{~kJ} \cdot \mathrm{mol}^{-1}\end{array}$ \\
\hline \multirow{3}{*}{ NC-F } & Ozawa & 129.13 & 125.08 \\
\cline { 2 - 4 } & Kissinger & 127.75 & 123.71 \\
\cline { 2 - 4 } & simulation & 97.60 & 97.19 \\
\hline \multirow{3}{*}{ NC-C } & Ozawa & 105.33 & 101.23 \\
\cline { 2 - 4 } & Kissinger & 102.71 & 98.66 \\
\cline { 2 - 4 } & simulation & 75.45 & 75.05 \\
\hline
\end{tabular}

\section{CONCLUSIONS}

Both NC-F and NC-C have $20-30 \mu \mathrm{m}$ average size in diameter. NC fibers with plasticizer DBP present a molten state, and attach to each other more closely than those with humectant isopropanol.

A part of humectant will volatilize before $\mathrm{NC}-\mathrm{F}$ decomposes. The decomposition reactions of both $\mathrm{NC}-\mathrm{F}$ and NC-C follow the single-stage autocatalytic reaction and the decomposition temperature of both two samples increases with the increasing heating rate. The initial decomposition temperature of $\mathrm{NC}-\mathrm{C}$ is lower than that of $\mathrm{NC}-\mathrm{F}$. Moreover, the decomposition temperature range of $\mathrm{NC}-\mathrm{C}$ is larger than NC-F due to the effect of the plasticizer DBP.

In addition, the thermal kinetic parameters calculated based on Ozawa method are approximately consistent with those based on Kissinger method. However, the parameters of NC-F including the activation energy and enthalpy of activation are larger than those of NC-C. Autocatalytic simulation is in positive compliance with the DSC curves of the two NC mixtures. The calculated thermal kinetic parameters based on simulation is much lower than those based on Ozawa and Kissinger methods.

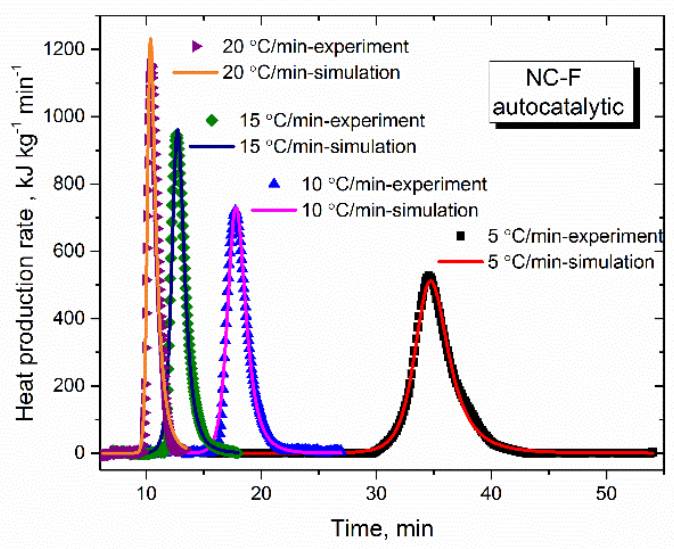

a

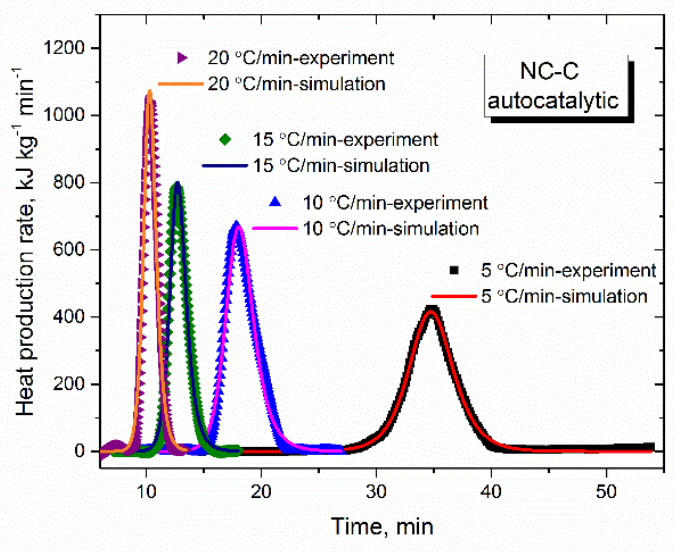

b

Fig. 7. The comparison between experiments and autocatalytic simulation on: $\mathrm{a}-\mathrm{NC}-\mathrm{F} ; \mathrm{b}-\mathrm{NC}-\mathrm{C}$

\section{Acknowledgments}

This research was supported by the National Natural Science Foundation of China (No. 51376172).

\section{REFERENCES}

1. Katoh, K., Soramoto, T., Higashi, E., Kawaguchi, S., Kumagae, K., Ito, S., Wada, Y., Nakano, K., Arai, M. Influence of Water on the Thermal Stability of Nitrocellulose Science and Technology of Energetic Materials 75(1-2) 2014: pp. $44-49$.

http://id.ndl.go.jp/bib/025509513

2. Guo, S., Wang, Q., Sun, J., Liao, X., Wang, Z.S. Study on The Influence of Moisture Content on Thermal Stability of Propellant Journal of Hazardous Materials 168 (1) 2009: pp. 536-541.

https://doi.org/10.1016/j.jhazmat.2009.02.073

3. Fu, G., Wang, J., Yan, M. Anatomy of Tianjin Port Fire and Explosion: Process and Causes Process Safety Progress 35 (3) 2016: pp. 216-220.

https://doi.org/10.1002/prs.11837

4. Katoh, K., Higashi, E., Ariyoshi, Y., Wada, Y., Nakano, K. Relationship Between Accidents Involving Spontaneous Ignition of Nitric Acid Esters and Weather Conditions Science \& Technology of Energetic Materials 5-6 2013: pp. $132-137$. http://id.ndl.go.jp/bib/025122915 
5. Wei, R., He, Y., Zhang, Z., He, J., Yuen, R., Wang, J. Effect of Different Humectant on the Thermal Stability and Fire Hazard of Nitrocellulose Journal of Thermal Analysis and Calorimetry 133 (3) 2018: pp. 1291-1307.

https://doi.org/10.1007/s10973-018-7235-6

6. Katoh, K., Le, L., Itoh, M., Arai, M., Tamura, M. Study on the Spontaneous Ignition of Cellulose Nitrate: Effect of the Type of Storage Atmosphere (I) Science \& Technology of Energetic Materials 64 (6) 2003: pp. 236-240.

http://id.ndl.go.jp/bib/6837269

7. Katoh, K., Le, L., Arai, M., Tamura, M. Study on the Spontaneous Ignition of Cellulose Nitrate: Effect of the Type of Storage Atmosphere (II) Science \& Technology of Energetic Materials 65 (3) 2004: pp. 77-81.

8. Fathollahi, M., Pourmortazavi, S.M., Hosseini, S.G. The Effect of the Particle Size of Potassium Chlorate in Pyrotechnic Compositions Combustion \& Flame 138 (3) 2004: pp. 304-306.

https://doi.org/10.1016/j.combustflame.2004.06.001

9. Kotoyori, T. Critical Ignition Temperatures of Wood Sawdusts Fire Safety Science 1 1986: pp. 463-471. https://doi.org/10.3801/iafss.fss.1-463

10. Hu, L.H., Huo, R., Li, Y.Z., Wang, H.B. Experimental Study on the Burning Characteristics of Wood Cribs in a Confined Space Journal of Fire Sciences $22(6)$ 2004: pp. $473-489$.

https://doi.org/10.1177/0734904104042595

11. Wakefield, T., He, Y., Dowling, V.P. An Experimental Study of Solid Timber External Wall Performance under Simulated Bushfire Attack Building \& Environment 44 (10) 2009: pp. $2150-2157$. https://doi.org/10.1016/j.buildenv.2009.03.005

12. Wei, R., He, Y., Liu, J., He, Y., Mi, W., Yuen, R., Wang, J. Experimental Study on the Fire Properties of Nitrocellulose with Different Structures Materials 10 (3) 2017: pp. 316. https://doi.org/10.3390/ma10030316

13. Phillips, R.W., Orlick, C.A., Steinberger, R. The Kinetics of the Thermal Decomposition of Nitrocellulose Journal of Physical Chemistry 59 (10) 1955: pp. 1034-1039. https://doi.org/10.1021/j150532a011

14. Sovizi, M.R., Hajimirsadeghi, S.S., Naderizadeh, B. Effect of Particle Size on Thermal Decomposition of Nitrocellulose Journal of Hazardous Materials $168(2-3)$ 2009: pp. $1134-1139$.

https://doi.org/10.1016/j.jhazmat.2009.02.146

15. Hosseini, S.G., Pourmortazavi, S.M., Hajimirsadeghi, S.S. Thermal Decomposition of Pyrotechnic Mixtures Containing Sucrose with Either Potassium Chlorate or Potassium Perchlorate Combustion and Flame 141 (3) 2005: pp. 322-326.

https://doi.org/10.1016/j.combustflame.2005.01.002

16. Ramos, L.A., Cavalheiro, É.T.G., Chierice, G.O. Preparation, Characterization and Thermal Decomposition of Ammonium Salts of Dithiocarbamic Acids Journal of Thermal Analysis and Calorimetry 79 (2) 2005: pp. $349-353$.

https://doi.org/10.1007/s10973-005-0063-5

17. Scanes, F.S. Thermal Analysis of Pyrotechnic Compositions Containing Potassium Chlorate and Lactose Combustion \& Flame 23 (3) 1974: pp. 363-371. https://doi.org/10.1016/0010-2180(74)90119-9

18. Pourmortazavi, S.M., Hajimirsadeghi, S.S., Hosseini, S.G. Characterization of the Aluminum/Potassium Chlorate Mixtures by Simultaneous TG-DTA Journal of Thermal Analysis and Calorimetry 84 (3) 2006: pp. $557-561$. https://doi.org/10.1007/s10973-005-7008-x

19. Rong, L., Binke, N., Yuan, W., Zhengquan, Y., Hu, R. Estimation of the Critical Temperature of Thermal Explosion for the Highly Nitrated Nitrocellulose Using Non-isothermal DSC Journal of Thermal Analysis and Calorimetry 58 (2) 1999: pp. 369-373.

https://doi.org/10.1023/a:1010155221958

20. Pourmortazavi, S., Hosseini, S., Rahimi-Nasrabadi, M., Hajimirsadeghi, S., Momenian, H. Effect of Nitrate Content on Thermal Decomposition of Nitrocellulose Journal of Hazardous Materials 162 (2) 2009: pp. $1141-1144$. https://doi.org/10.1016/j.jhazmat.2008.05.161

21. Wei, R., Huang, S., Wang, Z., Yuen, R., Wang, J. Evaluation of the Critical Safety Temperature of Nitrocellulose in Different Forms 56 2018: pp. 289-299. https://doi.org/10.1016/j.jlp.2018.09.004

22. You, M.L., Liu, M.Y., Wu, S.H., Chi, J.H., Shu, C.M. Thermal Explosion and Runaway Reaction Simulation of Lauroyl Peroxide by DSC Tests Journal of Thermal Analysis and Calorimetry 96 (3) 2009: pp. 777-782. https://doi.org/10.1007/s10973-009-0025-4

23. Lin, C.P., Li, J.S., Tseng, J.M., Mannan, M.S. Thermal Runaway Reaction for Highly Exothermic Material in Safe Storage Temperature Journal of Loss Prevention in the Process Industries 40 2016: pp. 259-265. https://doi.org/10.1016/j.jlp.2016.01.006

24. Lin, C.P., Tseng, J.M., Chang, Y.M., Cheng, Y.C., Lin, H.Y., Chien, C.Y. Green Thermal Analysis for Predicting Thermal Hazard of Storage and Transportation Safety for Tert-butyl Peroxybenzoate Journal of Loss Prevention in the Process Industries 25 (1) 2012: pp. 1-7. https://doi.org/10.1016/j.jlp.2011.06.027

25. Lin, C.P., Chang, Y.M., Tseng, J.M., Shu, C.M. Comparisons of Nth-order Kinetic Algorithms and Kinetic Model Simulation on HMX by DSC tests Journal of Thermal Analysis \& Calorimetry 100 (2) 2010: pp. 607-614. https://doi.org/10.1007/s10973-009-0592-4

26. Lin, C.P., Chang, C.P., Chou, Y.C., Chu, Y.C., Shu, C.M. Modeling Solid Thermal Explosion Containment on Reactor HNIW and HMX Journal of Hazardous Materials $176(1-3)$ 2010: pp. 549-558. https://doi.org/10.1016/j.jhazmat.2009.11.064

27. Ozawa, T. A New Method of Analyzing Thermogravimetric Data Bulletin of the Chemical Society of Japan 38 (11) 1965: pp. $1881-1886$. https://doi.org/10.1246/bcsj.38.1881

28. Kissinger, H.E. Reaction Kinetics in Differential Thermal Analysis Analytical Chemistry 29 (11) 1957: pp. $1702-1706$. https://doi.org/10.1021/ac60131a045

29. Jessup, R.S., Prosen, E. Heats of Combustion and Formation of Cellulose and Nitrocellulose (Cellulose Nitrate) Journal of Research of the National Bureau Standards 44 1950: pp. 387. https://doi.org/10.6028/jres.044.034

30. Olszak Humienik, M., Mozejko, J. Thermodynamic Functions of Activated Complexes Created in Thermal Decomposition Processes of Sulphates Thermochimica Acta 344 (1) 2000: pp. $73-79$. https://doi.org/10.1016/s0040-6031(99)00329-9

31. Straszko, J., Olszak Humienik, M., Możejko, J. Kinetics of Thermal Decomposition of $\mathrm{ZnSO}_{4} \cdot 7 \mathrm{H}_{2} \mathrm{O}$ Thermochimica Acta $292(1-2)$ 1997: pp. $145-150$. https://doi.org/10.1016/s0040-6031(96)03114-0 